\title{
LA MOCION DE CENSURA EN LA ADMINISTRACION LOCAL
}

$342.531: 352$

por

\section{Manuel Rebollo Puig}

Profesor Ayudante de Derecho Administrativo de la Universidad de Córdoba

SUMARIO: I. LA MOCION DE CENSURA EN EL AMBITO MUNICIPAL: 1. LA MOCIÓN DE CENSURA COMO TÉCNICA DE RELACIÓN ENtre los Poderes legislativo y ejecutivo. 2. Precedentes. 3. VALORACIÓN CRITICA DE LA MOCIÓN DE CENSURA. 4. La MOCIÓN DE CENSURA COMO MATERIA RESERVADA A LA LEY ORGANICA.-II. LA MOCION DE CENSURA AL PRESIDENTE DE LA DIPUTACION. REFERENCIA A LAS MANCOMUNIDADES INTERINSULARES, CABILDOS Y CONSEJOS INSULARES.

\section{LA MOCION DE CENSURA EN EL AMBITO MUNICIPAL}

La moción de censura en el Régimen local ha sido uno de los temas más debatidos en los últimos años, tanto en el ámbito de la política local como en la jurisprudencia de nuestros más altos Tribunales. No es casual, por ello, que la moción de censura de los Presidentes de Corporaciones locales haya sido objeto de especial atención tanto por parte de la Ley Reguladora de las Bases del Régimen local, como por la Ley de Régimen Electoral General, a la que corresponde su regulación sustantiva.

La Ley 7/1982, de 2 de abril, Reguladora de las Bases del Régimen local, en su artículo 22, 3, establece: 
«Pertenece igualmente al Pleno la votación sobre la moción de censura al Alcalde, que se rige por lo dispuesto en la legislación electoral general».

En iguales términos recoge tal competencia el párrafo 3 del artículo 33, respecto al Pleno y Presidente de la Diputación.

Nos centraremos inicialmente en la moción de censura en el ámbito municipal.

La remisión del transcrito párrafo 3 del artículo 22 ha de entenderse hecha al artículo 197 de la Ley Orgánica 5/1985, de 19 de junio, de Régimen Electoral General, según el cual:

1. El Alcalde puede ser destituido de su cargo mediante moción de censura adoptada por la mayoría absoluta del número. legal de Concejales.

2. La moción debe ser suscrita, al menos, por la tercera parte de los Concejales e incluir el nombre del candidato propuesto para Alcalde, quien quedará proclamado como tal en caso. de prosperar la moción de censura.

3. A los efectos previstos en el presente artículo, todos los Concejales pueden ser candidatos.

Hasta llegar a esta redacción, la moción de censura al Alcalde pasó en el debate parlamentario por distintas vicisitudes; fundamentalmente, su trasvase del proyecto de Ley Reguladora de las. Bases de Régimen local, que inicialmente afrontaba su completa regulación, al de la Ley Electoral, con el significado consiguiente a su inclusión en la Ley Orgánica (1), que posteriormente analizaremos.

El texto del artículo 21 del Proyecto de Ley Reguladora de las Bases del Régimen local, aprobado inicialmente por el Consejo de Ministros (2), establecía en su párrafo 3 lo siguiente:

«Pertenece igualmente al Pleno la votación sobre la moción de censura al Alcalde, que sólo podrá adoptarse por mayoría de dos: tercios del número legal de Concejales.

(1) Es en el trámite de ponencia en el Senado cuando, aceptándose una enmienda del Grupo Popular, se opt 6 por convertir el artículo 22, 3, de la LRBRL en una simple remisión a la legislación electoral general (Boletín Oficial de las Cortes Generales, Senado, serie II, núm. 215, d), del 12 de febrero de 1985, pág. 287).

(2) Publicado en el Boletín Oficial de las Cortes Generales, Congreso de los: Diputados, serie A, núm. 97-I, del 3 de abril de 1984. 
La moción debe ser suscrita por, al menos, la tercera parte de los Concejales e incluir el nombre del candidato propuesto para Alcalde, quien quedará proclamado como tal en caso de prosperar la moción.

Sólo podrán ser candidatos los Concejales que figuraron en los tres primeros puestos y, en su caso, los siguientes por el orden de las listas electorales cuando alguno de aquéllos hubiera perdido la condición de Concejal. Ningún Concejal puede suscribir durante su mandato más de una moción de censura».

Como se verá, las modificaciones concretas de la inicial redacción han tendido a facilitar el planteamiento de la moción por dos vías:

a) Exigencia de mayoría absoluta, y no de dos tercios, para la adopción de la moción.

b) Ampliación a todos los Concejales, y no sólo a los tres primeros de cada lista, de la posibilidad de ser candidato a la Alcaldía por esta vía.

En este sentido, aunque en una u otra dirección, se movieron la mayoría de las distintas enmiendas presentadas, tanto en el debate del artículo 22, 3, de la Ley Reguladora de las Bases del Régimen local, como en el artículo 197 de la Ley Orgánica de Régimen Electoral General, pero en ningún caso se cuestionó la misma admisión de la figura.

Tal recepción de la moción de censura se produce, además, y es importante destacarlo desde ahora, sin alterar, salvo en aspectos irrelevantes a estos efectos, el sistema de elección de Alcalde. Así, el artículo 196 de la Ley Electoral es sustancialmente igual al 28, 3, de la Ley de Elecciones locales, a excepción de las especialidades introducidas para Municipios comprendidos entre 100 y 250 habitantes y la sustitución del criterio de la edad por el del sorteo para dirimir posibles empates. Por lo demás, y en lo que ahora interesa, se mantiene la exigencia de encabezar la respectiva lista electoral para ser candidato a la Alcaldía y la posibilidad de ser proclamado Alcalde, sin la mayoría absoluta del voto de los Concejales, por encabezar la lista de mayor número de votos populares. 
1. La MOCIÓN DE CENSURA COMO TÉCNICA DE RELACIÓN ENTRE LOS PoDERES Legislativo y eJeCUTIVo

Los artículos 197 de la Ley Orgánica de Régimen Electoral General y 22, 3, de la Ley Reguladora de las Bases del Régimen local suponen la introducción en el Régimen local de una técnica propia de las relaciones entre el Poder legislativo y el ejecutivo, entre Parlamento y Gobierno. En efecto, la moción de censura es, en los regímenes de división de poderes, una especie de flexibilización o modulación de la absoluta separación de poder, en tanto que hace depender la permanencia del Gobierno de la voluntad del Parlamento en cualquier momento de la legislatura y no sólo en la investidura (3). Por ello, no sin razón, se califica a estos regímenes de separación de poderes «elástica» o "matizada» frente al régimen presidencial o de separación «rígida» o «tajante» (4).

Naturalmente, su reconocimiento o negación no es una opción autónoma separable del marco general de relaciones entre los poderes constitucionales y, concretamente, entre Parlamento y Gobierno. Por el contrario, es el resultado de una decisión previa: La forma de elección del Jefe del Gobierno. Cuando éste deriva su mandato de una elecciones específicamente encaminadas a su proclamación y con sufragio universal, directo o indirecto, no es posible conceder al Parlamento poder para destituir al elegido por los ciudadanos. No sólo la lógica institucional del sistema veda tal posibilidad. El origen popular del Presidente, salido de unas elecciones de ámbito nacional, a diferencia de los parlamentarios, le confiere una legitimación y un prestigio que hacen políticamente difícil la articulación de la censura. Basta para corroborarlo la experiencia francesa, en donde la superposición, sobre un régimen parlamentario, de la elección por sufragio universal del Presidente de la República ha sido suficiente para alterar las relaciones entre los poderes, potenciando al Ejecutivo hasta el punto de ser confi-

(3) Concretamente, «la moción de censura ha sido considerada tradicionalmente como una característica imprescindible de los sistemas parlamentarios $y$, a la vez, esencia misma del parlamentarismo...». Montero Gibert, J. R.: Voz «Moción de censura», en Diccionario del Sistema Político Español, dirigido por J. J. GonzÁlez ENCINAR, Madrid, 1984, pág. 505.

(4) Véase Hauriou, A.; Gicquel, J., y GÉlard, P.: Derecho constitucional $e$ instituciones políticas. Barcelona, 1980, 2." edic., pág. 267. 
gurado como un tercer género, expresivamente calificado como régimen semipresidencial (5).

La moción de censura, pues, encuentra justificación cuando el Jefe del Gobierno es investido por el mismo Parlamento. Aun así, su reconocimiento suele ser compensado, para mantener cierto equilibrio entre los poderes, con la posibilidad del Gobierno o de su Presidente de disolver las Cámaras legislativas convocando al mismo tiempo nuevas elecciones, lo que, en alguna medida, supone solucionar la crisis entre los poderes constitucionales mediante el arbitraje popular. Es esta disolución de las Cámaras y nuevo llamamiento al electorado una pieza esencial del régimen parlamentario, que permite conjugar la soberanía del Parlamento con la autoridad y estabilidad del Gobierno. Con justicia se calificó a los regímenes que consagran la investidura parlamentaria y la moción de censura, sin la correlativa posibilidad de disolución de las Cámaras por el Ejecutivo, de régimen de asambleas porque el equilibrio se rompe en favor de ésta, convirtiendo al Gobierno - se ha dicho- en un «recadero» de aquélla, hasta el punto de que difícilmente puede hablarse de una efectiva división de poderes (6).

Como es sabido, nuestra Constitución, congruente con la consagración de la "Monarquía parlamentaria», del párrafo $3 .^{\circ}$ de su artículo 1, recoge la investidura parlamentaria (art. 99), la cuestión de confianza (arts. 112 y 114, 1), la disolución de las Cortes o de alguna de las Cámaras (art. 115) y la moción de censura (arts. 113 y 114, 2). La configuración constitucional de esta última, con criterios restrictivos y como moción constructiva, ha influido en su recepción y regulación en el Régimen local. Ello se patentiza desde la misma utilización de la expresión "moción de censura", novedosa en nuestro Régimen local -no así la institución misma, según veremos-y que inevitablemente evoca la técnica parlamentaria, hasta en los últimos detalles de su regulación: exigencia de que la propuesta sea presentada por un mínimo de Concejales e incluya el nombre de un candidato (moción constructiva), exigencias de una mayoría cualificada para su aprobación y limitación a los mismos

(5) Véase, al respecto, Duverger, M.: Instituciones políticas y Derecho constitucional. Barcelona, 1980, 6." edic., págs. 152 y sigs.; en concreto, señala: "... el régimen semipresidencial tiene más de régimen parlamentario que de régimen presidencial... La diferencia fundamental es que la elección por sufragio universal convierte al Jefe del Estado en un representante del pueblo...».

(6) Duverger, M.: Instituciones políticas y Derecho constitucional, op. cit., página 157. 
proponentes de nuevas mociones, parecen recordar claramente el artículo 113 de la Constitución (7).

No es ello algo casual. Por el contrario, las relaciones entre Parlamento y Gobierno y su traslación al ámbito de la Administración local, y más concretamente a la municipal, han aflorado continua y reiteradamente al debate parlamentario de la Ley, y, curiosamente, tal inspiración en el sistema de relaciones entre Gobierno y Cortes se presenta por los parlamentarios de la mayoría como algo positivo. Merece ser recogida la afirmación del Senador TRAPERo GARCía, quien abiertamente afirmaba que «lo que la Ley prevé, en principio, es un sistema parlamentario eficaz y un sistema parlamentario equilibrado" (8). No se trata, pues, de cierto paralelismo, sino de la sorprendente creencia de que se estaba instaurando un verdadero régimen parlamentario en los Ayuntamientos. Nos ocuparemos posteriormente de la inviabilidad de tal planteamiento. Bástenos señalar aquí cómo la consagración de la moción de censura al Alcalde se incardina en esta tendencia (9).

\section{Precedentes}

Pese a ser, como se ha venido exponiendo, la moción de censura una fórmula incardinable, y generalmente incardinada, en las relaciones entre el Poder legislativo y ejecutivo, no puede afirmarse que su recepción constituya una novedad absoluta en nuestro Régimen local. Para el Presidente de la Diputación, lo recogía el artículo 34, 3, de la Ley de Elecciones Locales de 17 de julio de 1978. También está establecida en las normas forales de las Diputaciones vascas (10). Pero incluso con referencia al Alcalde, ha estado consagrada en nuestro Derecho.

(7) El paralelismo con la regulación de la moción de censura establecido en el artículo 113 de la Constitución ha sido ya puesto de relieve. Véase Cosculluela MoNTANER, L. M.: «Organización y régimen jurídico de las Entidades locales. La función pública local», en Organización territorial del Estado (Administración local), Madrid, 1985, vol. I, pág. 133, y García-Escudero Márquez, P., y Pendás Garcfa, B.: El nuevo Régimen local español. Estudio sistemático de la Ley 7/1985, de 2 de abril, Reguladora de las Bases del Régimen local. Barcelona, 1985, pág. 222.

(8) Sesión del Pleno del Senado del 20 de febrero de 1985, en Diario de Sesiones del Senado, pág. 5188.

(9) En este sentido, García-Escudero Márouez, P., y Pendás García, B., afirman que la moción de censura es "congruente con el sistema parlamentario que inspira la nueva organización municipal», El nuevo Régimen local español. Estudio sistemático de la Ley 7/1985, de 2 de abril, Reguladora de las Bases del Régimen local. Barcelona, 1985, pág. 222.

(10) Artículo 32 de la Norma del 26 de febrero de 1983 sobre la Organización Institucional del Territorio de Guipúzcoa (Boletín Oficial del País Vasco, núm. 29, 
En nuestro Régimen local ha sido frecuente la designación de los Alcaldes por las autoridades de la Administración del Estado. Al Rey u órganos centrales, en unos casos, y a los Jefes políticos y Gobernadores, en otros, ha correspondido, en base a la consideración del Alcalde como delegado del Gobierno en el Municipio, la designación de éste (11). Así se establecía, por ejemplo, en el Real Decreto para el arreglo provisional de los Ayuntamientos del Reino de 23 de julio de 1835 (art. 31: «Los Gobernadores civiles, recibida que sea la elección y decididas las reclamaciones, si las hubiere, nombrarán para Alcalde a uno de los tres que haya tenido mayor número de votos... "). Igualmente, la Ley de Ayuntamientos de 14 de julio de 1840, salvo en los Municipios de menos de 500 vecinos (artículo 45), si bien, tras la reforma de 30 de diciembre de 1843 , se generalizó el sistema de elección popular para todos los Municipios. De nuevo, la Ley de Organización y Atribuciones de los Ayuntamientos de 8 de enero de 1845 consagraba el sistema de designación (artículo 9: «Los Alcaldes serán nombrados por el Rey en todas las capitales de Provincia y en las cabezas de partido judicial cuya población llegue a 2.000 habitantes. En los demás pueblos, los nombrará el Jefe político por delegación del Rey»). Tras un período en que se abandona, la Ley de 2 de octubre de 1877 lo reimplanta, con la excepción de los pequeños Municipios (art. 49). Huelga señalar que con tales procedimientos de designación de Alcalde no tiene sentido la moción de censura, que, naturalmente, no recogía la legislación.

A igual conclusión ha de llegarse en el supuesto de elección directa por los vecinos, sistema éste preferentemente acogido en nuestras Leyes del pasado siglo cuando se optaba por el carácter representativo del Alcalde: Acogieron este sistema el ya citado Real Decreto de 30 de diciembre de 1843, la Ley de Ayuntamiento de 5 de julio de

del 9 de marzo), y artículo 32 de las Normas del 5 de enero de 1983, de Organización de las Juntas Generales y Diputación Foral de Vizcaya (Boletín Oficial del País Vasco, núm. 34, del 21 de marzo).

(11) Sobre los orígenes, justificación y evolución de este sistema de designación del Alcalde, en lo que no nos podemos detener aquí, puede verse Morillo-VelarDE, J. L.: El Alcalde en la Administración española. Sevilla, 1977, en especial páginas 181 y sigs. Concretamente señala que como el Alcalde «es considerado a la vez el administrador supremo de los intereses del común y el agente del Poder ejecutivo, su articulación ha de realizarse siguiendo la dinámica propia de estos dos aspectos, lo que significa participando de la nota de la representatividad y, además, de la necesidad de salvaguardar la confianza del Poder en quién lo va a vincular con sus actuaciones» (pág. 182).

Sobre la influencia de esta solución del modelo de Administración napoleónica, puede verse GARCf́A DE ENTERRfA, E.: «Administración periférica del Estado: problemas de articulación», en Administración Española, Madrid, 1964, pág. 124. 
1856 y la Ley municipal puesta en vigor por el Decreto de 21 de octubre de 1868 (art. 25). Tampoco en este supuesto de elección directa tiene justificación la censura, pues supondría otorgar a los Concejales la posibilidad de contradecir la voluntad expresada por el electorado. La representatividad y legitimación del Alcalde derivan en estos supuestos directamente del pueblo y no de los Concejales, por lo que carece de sentido conferirles la posibilidad de destituir a aquél (12).

A imagen de las relaciones entre los Poderes legislativo y ejecutivo, sólo resulta justificable y admisible la moción de censura en los casos en que la designación del Alcalde corresponde al Pleno. Es esto precisamente lo que carece de tradición en nuestro Derecho, no tanto por la inexistencia de normas en este sentido como por su escasa vigencia real. Tal designación por los Concejales se recogía en la Ley de 20 de agosto de 1870; en el Estatuto municipal, que no llegó a aplicarse en lo referente a elecciones y constitución de las Corporaciones; en la efímera Ley republicana de 31 de octubre de 1935, y en la Ley de Bases de 19 de noviembre de 1975. De estas cuatro Leyes, dos recogen la moción de censura, aunque sin usar tal denominación:

a) Estatuto municipal. Su artículo 102 establecía que el Alcalde "podrá ser destituido por acuerdo de dos terceras partes del número legal de Concejales». Junto a ello, cabía igualmente la destitución por referéndum previa petición de las tres cuartas partes del número legal de Concejales o de la vigésima de electores (art. 219).

b) Ley municipal de 31 de octubre de 1935. Es ésta un claro exponente de la relación entre la forma de elección del Alcalde y la admisión o no de la moción de censura. Se establecían dos formas de designación de Alcalde: «Por elección directa del pueblo o por el Ayuntamiento" (art. 73), dándose preferencia a aquélla (arts. 76 y 51). Congruentemente con esta diversidad de sistemas de elección, se reconocía la posibilidad de destitución del Alcalde "por el voto de la mayoría absoluta de los Concejales que legalmente formen la Corporación", sólo en el supuesto en que hubiese sido elegido por el Ayuntamiento. El Alcalde elegido por los vecinos sólo podía ser

(12) Por el contrario, se conecta en estos casos la destitución del Alcalde a una decisión judicial, especificándose paralelamente, y en la medida de lo posible, las causas que pudiera provocarlas. Puede verse, sobre ello, Morillo-Velarde, J. L.: El Alcalde..., op. cit., págs. 204 y 309 y sigs. 
destituido por «votación popular en que así lo acuerde la mitad más uno de los electores» (art. 81).

La Ley de Elecciones locales de 17 de julio de 1978, modificada en aspectos que no afectan al tema que nos ocupa por la de 2 de marzo de 1983, no recogía la posibilidad de destitución del Alcalde por los Concejales. La omisión era indicativa de la negación de competencia al Pleno para destituir al Presidente de la Corporación, por las razones que luego se expondrán. Pero pese a ello, bajo su vigencia se ha producido su aceptación jurisprudencial o así, al menos, se ha querido ver (13).

Nos referimos, en concreto, a la sentencia del Tribunal Supremo de 14 de julio de 1983 (R. Aranzadi 3993), dictada en recurso contra la anterior de la Audiencia Territorial de Granada de 6 de mayo de 1983, y contra la que, a su vez, interpuso recurso de amparo ante el Tribunal Constitucional, que fue declarado inadmisible por auto de 11 de enero de 1984.

En estas resoluciones se conoce del acuerdo, adoptado por unanimidad, del Pleno del Ayuntamiento de Rincón de la Victoria, por el que se destituía a su Alcalde, y en ambos casos con el límite, ya que el recurso contencioso-administrativo se entabló por la vía especial de la Ley de 26 de diciembre de 1978, de resolver sobre la violación de derechos fundamentales y libertades públicas, particularmente del consagrado en el artículo 23, 2, de la Constitución, sin posibilidad de entrar en cualquier otra infracción del ordenamiento jurídico por el acuerdo impugnado. De conformidad con ello, el citado auto del Tribunal Constitucional precisa que en la cuestión que se le somete hay dos problemas diferentes que conviene separar

(13) Es necesario aludir siquiera al precedente que sienta la sentencia del Tribunal Constitucional del 4 de febrero de 1983 (Boletin Oficial del Estado del 9 de marzo), que resolvió el recurso de amparo interpuesto por un Alcalde cesado como tal y como Concejal por haber sido expulsado de su Partido, en aplicación del artículo 11, 7, de la Ley del 17 de julio de 1978. Como es sabido, el Tribunal en ésta y otras sentencias estimo el amparo en cuanto al cese como Concejal, pero en cuanto al cargo de Alcalde, el fundamento jurídico 6 precisaba que use advierte en seguida que al cese en el cargo de Alcalde acordado por los Concejales, como consecuencia de entender aplicable el artículo 11, 7, sin modificación alguna, no le son aplicables las consideraciones expuestas en cuanto al cargo de Concejal, dado que aquí el cese se produce por los electores. Por ello, no se puede afirmar que se haya violado un derecho fundamental susceptible de amparo, ya que no puede entenderse que ha quedado vulnerado el derecho de los ciudadanos a participar en los asuntos públicos por medio de representantes elegidos por sufragio universal, puesto que la elección de Alcalde es de segundo gradon.

No se trata todavía de admitir la destitución del Alcalde por los Concejales, pero indudablemente dejaba abierta la posibilidad de tal destitución. 
con nitidez. De una parte, una cuestión de legalidad ordinaria; de otra, el de la pretendida violación del artículo 23,2 , de la Constitución, que constituye el objeto central del amparo solicitado. Es la inexistencia de tal violación, al considerar que el derecho a permanecer en los cargos públicos no resulta comprendido en el artículo 23,2 , de la Constitución, en el caso del Alcalde, la verdadera ratio decidendi de la inadmisión, y así verdaderamente habría de ser dado el conocimiento limitado que el recurso de amparo supone y su no asimilación a una tercera instancia, tantas veces reiterada por el mismo Tribunal. Por eso, acertadamente, señala el repetido auto que respecto al "plano de la legalidad ordinaria..., este Tribunal tiene en este momento únicamente que decir que la interpretación llevada a cabo por la Sala de lo Contencioso-administrativo de la Audiencia de Granada y por la Sala Tercera del Tribunal Supremo de Justicia ningún reparo puede ponérsele desde el punto de vista de la Constitución». No hay, pues, un reconocimiento frontal de la competencia del Pleno para destituir al Alcalde, sino únicamente de la no protección del destituido por la vía del amparo o, en palabras del mismo Tribunal, de que la «demanda no posee contenido constitucional».

En el mismo sentido y con el mismo reducido ámbito deberían entenderse las sentencias de la Audiencia Territorial de Granada de 6 de mayo de 1983 y del Tribunal Supremo de 14 de julio de 1983, dado que se producen en un proceso especial de la Ley 68/1978, de 26 de diciembre, de Protección Jurisdiccional de los Derechos Fundamentales de la Persona.

Sin embargo, es forzoso reconocer que en las resoluciones comentadas hay también un reconocimiento de la competencia de destitución. Las bases para tal conclusión son las siguientes:

- Existe, tras la declaración de inconstitucionalidad, por sentencia de 2 de febrero de 1981, del artículo 421 de la Ley de Régimen local, que atribuía al Ministro de la Gobernación o a los Gobernadores civiles la facultad de suspensión y destitución del Alcalde por razones de orden público, mala conducta o negligencia grave, "una laguna legal que el juzgador debe colmar mediante una interpretación sistemática del ordenamiento jurídico y un recurso a los principios generales" (fundamento jurídico 1, auto del Tribunal Constitucional).

- No aparece claramente, en ninguna de las dos resoluciones, 
cómo se ha realizado tal interpretación sistemática o a qué principios generales se ha acudido para admitir la destitución del Alcalde. Se alude al «espíritu que inspira y anima a una norma como la constitucional al regular la gestión de los Municipios..., porque ciertamente los artículos 137 y 140 son bien reveladores de una idea consecuente con unos principios políticos, que habrá de permitir en su obligado desarrollo la adopción de disposiciones con las que efectivamente dé cumplimiento a esa gestión de los Municipios formados por Concejales..." (considerando $2 .^{\circ}$ de la sentencia del Tribunal Supremo de 14 de julio de 1983). Se acude al reconocimiento de tal fórmula en el seno de la Diputación por el artículo 34, 3, de la Ley de Elecciones locales de 1978. Se refiere al precedente del artículo 81 de la Ley municipal de $1935 . .$. Pero, en definitiva, parece que el único argumento es la aplicación del principio del contrarius actus (14): En este sentido, la sentencia del Tribunal Supremo afirma que los Alcaldes, "como tales, son elegidos por los propios Concejales, y parece lógico atribuir a ese electorado la facultad de cesar como Alcalde al que un día fue elegido...». De hecho, es éste el único argumento de la sentencia que retiene el Tribunal Constitucional en el repetido auto:

«La mencionada sentencia de la Sala Tercera del Tribunal Supremo razona en este punto que el hecho de que sea la voluntad de los Concejales la que hace al Alcalde depositario de los destinos del Ayuntamiento..., permite sostener la posibilidad de destitución del Alcalde por el acuerdo de los Concejales".

Argumento éste que, como ya se ha dicho, no hace suyo el Tribunal Constitucional, limitándose a no oponerle reparo "desde el punto de vista de la Constitución".

No parece que los anteriores argumentos sean suficientes para admitir la posibilidad de destitución del Alcalde por los Concejales, bajo la vigencia de la Ley de Elecciones locales de 1978. Por el contrario, entendemos que la solución contraria se impone por las siguientes razones:

a) El punto de partida de la existencia de una «laguna legal» resulta difícilmente comprensible, pues no puede calificarse de tal

(14) Expresivamene lo formula VILLAR BoRDA, precisamente referido a la revocabilidad del mandato de los Alcaldes, afirmando que «las cosas se deshacen como se hacen», en Democracia municipal, Madrid, 1984, pág. 343. 
a la no atribución a un órgano de determinada competencia. Ello sencillamente significará que no tiene tal competencia: "Lege silente, la Administración carece de poderes, pues no tiene otros que los que la Ley le atribuye" (15).

Podría entenderse que la «laguna legal» a que se refiere el Tribunal Constitucional, consiste en la inexistencia de fórmulas que permitan la destitución del Alcalde por razones de orden público, mala conducta o negligencia grave, dejando desprotegido, en este punto, el interés público; de hecho, tal laguna la conecta con la declaración de inconstitucionalidad del artículo 421 de la Ley de Régimen local de 1955. Ello, a lo sumo, podría considerarse un aspecto criticable del ordenamiento, pero no una laguna que permita la atribución de poderes no previstos. Además, el mismo Tribunal Constitucional, en su sentencia de 2 de febrero de 1981 (16), sólo declaró la inconstitucionalidad parcial del citado artículo 421, precisando que «el interés general en presencia queda garantizado con la habilitación para suspenderlos (a los Alcaldes) por un plazo máximo de sesenta días», facultad que subsistía (17).

b) Derivar de la competencia del Pleno para elegir al Alcalde, la de destituirlo, sin ninguna base legal, porque "parece lógico", es, en nuestra opinión, erróneo.

(15) García de Entrrrfa, E., y Fernández Rodríguez, T. R.: Curso de Derecho administrativo. I, 4." ed., reimpresión revisada, Madrid, 1984, pág. 425. La cita transcrita se refiere a la atribución de potestad a la Administración, pero no parece que pueda encontrarse dificultad a su aplicación al supuesto concreto que nos ocupa. Interesa resaltar que a lo anterior se suma, en lo que se refiere a atribución de poderes - potestades, que la «interpretación extensiva o la aplicación de la analogía están aquí más bien excluidas de principio», op. cit., pág. 426.

Así, comentando la sentencia del 14 de julio de 1983, dice Cosculluela MontaNER, L. M., que «la moción de censura constituye, según apreciación del Tribunal Supremo, una laguna legal de nuestro ordenamiento, aunque bien pudiera entenderse, por el contrario, que la moción de censura no está deliberadamente prevista en la Ley de Elecciones locales», en Organización y régimen jurídico..., op. cit., pág. 133.

(16) Boletín Oficial del Estado, núm. 47, suplemento del 24 de febrero. En particular, véase el fundamento jurídico 10 , apartado $\mathrm{C}$.

(17) Sin duda, en la afirmación de la existencia de una laguna legal y en toda la construcción posterior pesó la singularidad y gravedad de los hechos que habían dado origen al acuerdo de distribución que explican, aunque no justifican jurídicamente, la solución adoptada.

Así, a través del primer considerando de la sentencia del Tribunal Supremo del 14 de julio de 1983, podemos conocer que se denunciaba «injurias graves contra la totalidad de los miembros de la Corporación... la extralimitación de funciones; el haber invadido repetidas veces atribuciones judiciales, anulando acuerdos del Ayuntamiento; el abandono de sus funciones al no haber convocado Permanente alguna desde que se incorporó a la Alcaldía; ... nombramientos ilegales; malversación de caudales...».

Pero, obviamente, las consecuencias de la solución jurisprudencial desbordan estos supuestos permitiendo la destitución con independencia de la causa que la motive. 
Por lo pronto, son innumerables los ejemplos en sentido contrario; es más, aun permaneciendo dentro del campo electoral, la imposibilidad de destitución por los electores constituye la regla general y esencia del llamado «mandato representativo» (18). Pero, además, la posibilidad de destitución afecta de modo tan esencial al sistema de relaciones entre los órganos, que resulta insostenible su recepción ante el silencio de la Ley.

c) Se ha partido, además, de un dato parcialmente inexacto, en tanto que, conforme al artículo 28,4 , de la Ley de Elecciones locales vigente en aquel momento, era posible la proclamación de Alcalde sin el acuerdo del Pleno por encabezar la lista con mayor número de votos populares. En tal caso resulta incongruente, además de infundado, conferir al Pleno la posibilidad de destitución (19).

d) El hecho de recoger expresamente la recientemente derogada Ley de Elecciones locales la destitución del Presidente de la Diputación, lejos de permitir una anormal aplicación analógica en el Municipio, patentizaba la voluntad de la Ley de no admitirla respecto al Alcalde, máxime cuando en el debate parlamentario fueron rechazadas dos enmiendas en tal sentido (20).

e) La recepción por vía jurisprudencial de la destitución de los Alcaldes por los Plenos sí que crea una laguna legal y, en este caso, difícilmente salvable. ¿Cuál había de ser el procedimiento a seguir? ¿Qué requisitos subjetivos y objetivos había de cumplir la proposición? ¿Cuál habrá de ser el quórum y la mayoría para aprobar la destitución, puesto que el Alcalde no había sido elegido por mayoría simple? ¿Quiénes podrían ser los nuevos candidatos? ¿Qué ocurriría si no se conseguía la mayoría absoluta para nombrar nuevo Alcalde?... Son algunas de las preguntas que planteaba la jurispru-

(18) Véase Hauriou, A.; Gicouel, J., y GÉlard, P.: Derecho constitucional..., op. cit., pág. 282, y Duverger, M.: Instituciones políticas..., op. cit., págs. 75 y sigs.

(19) En este sentido, ha señalado Rodríguez Moro, N., que «la tesis de la sentencia... no parece que tenga apoyo lógico suficiente en los casos a que se refiere la letra a) del apartado 3 del artículo $28 »$, en «El Alcalde puede ser destituido por los Concejales», RevisTa DE Estudios DE LA VIDA LOCAL, núm. 224, octubre-diciembre 1984, pág. 552.

Más rotundamente, Cosculluela Montaner, L. M., afirma que la «moción de censura es institucionalmente contradictoria con la designación del Alcalde, prevista en el artículo 28, 3 , de la Ley de Elecciones locales», en Organización y régimen jurídico..., op. cit., pág. 133.

(20) En el Pleno del Congreso se discutió y rechazó una enmienda de la «Minoría Catalana» sobre destitución del Alcalde.

En el Senado corrí igual suerte la enmienda de «Progresistas y Socialistas Independientes» sobre causas de cese del Alcalde, y entre ellas la destitución por el voto favorable de las dos terceras partes del número de Concejales. 
dencia comentada y a las que sólo podría contestarse con inseguridad y por la vía de interpretaciones forzosamente heterodoxas. Sólo el artículo 227, 2, del Reglamento de Organización, Funcionamiento y Régimen jurídico de las Corporaciones locales aludía a las "proposiciones de censura" para excepcionar el régimen de abstención de Alcaldes y Concejales en los acuerdos en que tengan interés directo, permitiendo al censurado permanecer y defenderse en las deliberaciones.

Aun con todo lo anterior, suficiente, en nuestra opinión, para concluir que la Ley de Elecciones locales no admitía la destitución del Alcalde por los Concejales, lo cierto es que las resoluciones comentadas constituyen, con independencia de su acierto, la realidad sobre la que operaban la Ley Reguladora de las Bases de Régimen local y la Ley Orgánica sobre Régimen Electoral General, el verdadero precedente tenido en cuenta. Desde este punto de vista, lo que la nueva Ley ha hecho no es instaurar la moción de censura, sino regularla y limitarla. En este sentido, merece una crítica positiva.

Sin embargo, hay que señalar que la construcción jurisprudencial comentada sigue constituyendo actualmente la única vía de destitución del Alcalde por el Pleno, ya que la nueva regulación de la moción de censura sólo será aplicable tras las próximas elecciones locales (Disposición Transitoria tercera de la Ley Orgánica de Régimen Electoral General).

\section{Valoración CRÍtica DE LA MOCIÓN DE CENSURA}

Lo dicho anteriormente sobre el origen parlamentario de la moción de censura y su conexión con la forma previamente seguida para la elección, son suficientes para comprender las dificultades que en nuestro sistema municipal puede plantear la recepción de esta forma de destitución del Alcalde.

El artículo 196 de la Ley Orgánica de Régimen Electoral General establece, como ya hacía el 28,3 , de la derogada Ley de Elecciones locales de 1978, la elección del Alcalde por el voto de la mayoría absoluta de los Concejales. Subsidiariamente, caso de no conseguirse tal mayoría, será proclamado el Concejal que encabece la lista más votada (21).

(21) Se trata, como se señalo respecto al contenido del artículo 28,3 , de la Ley de Elecciones locales, de un «sistema de compromiso entre un sistema de elección indirecta... y la pura atribución del puesto al primer candidato de la lista que hubiera obtenido más votos...». Cosculluela Montaner, L. M., y Muñoz Machado, S.: Las elecciones locales..., op. cit., pág. 302. 
Consecuentemente, cabe la proclamación de Alcalde sin la voluntad de los Concejales; mas no sólo es que no exista una segunda votación en la que baste la mayoría simple, sino que la designación está en función de la mayoría de votos populares y no de Concejales obtenidos, lo que es indicativo de la voluntad de la Ley de desvincular la designación de Alcalde de la decisión del Pleno. Ello parece conducir a considerar incongruente la admisión de la moción de censura.

Sin embargo, tal conclusión ha de ser, cuanto menos, matizada. La Ley no establece, como sí hacía la Ley municipal de 1935, una alternativa entre elección directa e indirecta del Alcalde, con la diferencia de dar preferencia a esta última. Por de pronto, el procedimiento subsidiario, recogido en el artículo 196, c), de la Ley Orgánica de Régimen Electoral General, no puede ser calificado estrictamente de elección directa en tanto que los electores no votan a distintos candidatos a la Alcaldía, sino a listas completas y cerradas de candidatos a Concejal (22). Sólo esto justifica y explica la preferencia del elegido por la mayoría absoluta de los Concejales al más votado por los vecinos.

Por otra parte, tampoco se consagran dos sistemas alternativos o subsidiarios. Se trata de un sistema con dos fases posibles, como puede serlo el de investidura del Presidente del Gobierno, en el que se sustituye una posible segunda votación por una proclamación directa. Es, simplemente, una solución de compromiso entre las distintas posiciones parlamentarias mantenidas en el debate de la Ley de Elecciones locales, que no desvirtúa el carácter indirecto de la elección y que mantiene ahora la nueva Ley Electoral.

Todo ello permite insertar la moción de censura en nuestro sistema electoral local: Aunque no parezca congruente conferir la posibilidad de destitución al Pleno cuando el Alcalde pudo ser proclamado sin su acuerdo, sí lo es en la medida en que el Pleno. constituye el "cuerpo electoral» natural y preferente del Alcalde. Así, puede decirse que la moción de censura acentúa este carácter, convirtiendo la elección de Alcalde por el Pleno en el sistema preferente en todo momento, y no sólo en la sesión constitutiva, quedando abierta siempre la posibilidad de las coaliciones que inicialmente

(22) En este sentido, se ha dicho respecto de la designación como Alcalde del cabeza de la lista más votada, que "... el elector, cuando expresa su voto, no lo hace directamente para nombrar Alcalde, sino para designar Concejales. Por tanto..., no puede calificarse de elección directa strictu sensu...». Cosculluela MONTANER, L. M., y Mữoz Machado, S.: Las elecciones locales..., op. cit., pág. 303, nota 13. 
no se lograron. Pero ello, que en sí puede resultar positivo, conlleva inevitablemente un riesgo de inestabilidad en la Administración municipal. El que el Alcalde cuente en todo momento con una mayoría real es, sin duda, positivo, como lo es el dar salida a las crisis encubiertas, a las que conduce la estabilidad del cargo. Pero en los casos en que, no lográndose inicialmente la mayoría absoluta, el Alcalde derive su condición de encabezar la lista más votada, la recepción de la moción de censura puede suponer una situación de crisis continua.

Este riesgo se acentúa y estimula al permitir la candidatura de todos los Concejales (art. 197, 3, de la Ley Orgánica de Régimen Electoral General), candidatura inicialmente limitada al cabeza de lista. Sin duda, esta aplicación de los candidatos favorece la posibilidad de coaliciones y hasta las estimula en el seno del partido mayoritario, que presentando un nuevo candidato quizá puede conseguir el apoyo de las minorías. Este último supuesto no parece que puede configurarse como excepcional. Por el contrario, en la práctica resultará difícil que prospere una moción de censura sin ser apoyada por el mismo partido del Alcalde censurado. La mayoría absoluta, exigida por el párrafo 1 del artículo 197 de la Ley Orgánica de Régimen Electoral General, así permite preverlo.

Consecuentemente con ello, no sólo se disminuye la estabilidad, sino que, en medida no desdeñable, se aleja al electorado de la decisión definitiva de elección de Alcalde. Ello se produce, además, en un sistema electoral de listas cerradas y bloqueadas, en el que el elector no tiene medios de expresar sus preferencias entre los distintos candidatos de cada lista. De esta forma, la influencia de la actuación de los partidos - tanto a través de la nominación y orden en que sean colocados los candidatos, como de decisiones posteriores al proceso electoral- en la proclamación de Alcalde será determinante. Lejos, pues, de consagrarse la elección directa del Alcalde por los vecinos, se opera en dirección contraria y precisamente en un campo como el local, en que, por su reducido ámbito y consecuente posibilidad de conocimiento de los candidatos, resulta cauce especialmente idóneo para la expresión de las preferencias personales y disminución parcial de la influencia de los partidos políticos (23).

(23) Se ha afirmado que la influencia de los partidos políticos en las elecciones está en función directa al tamaño de la circunscripción y, por tanto, en las más pequeñas aumenta la influencia de los factores personales. Ello, fundamentalmente, por dos causas: el conocimiento más directo de los candidatos y el coste de la campaña 
Tal vez más grave que lo anterior resulta la diversidad de requisitos para ser candidato a la Alcaldía, según el momento en que la elección se produzca. Así, en la sesión constitutiva sólo pueden ser elegidos aquellos que encabezaban su respectiva lista, mientras que posteriormente, mediante moción de censura, pueden serlo todos los Concejales.

Si el actual sistema de elección de Alcalde no permite, según hemos visto, una fácil recepción de la moción de censura, otro tanto puede decirse de las relaciones entre Pleno y Alcalde, jamás reconducibles a las del Parlamento y Gobierno, en las que la figura encuentra su origen, justificación y significado. Es cierto que la Ley Reguladora de las Bases del Régimen local da pasos en este sentido, como la configuración de la nueva Comisión del Gobierno, un reforzamiento de las competencias del Alcalde o la atribución específica al Pleno del "control y la fiscalización de los órganos de gobierno». Pero nada de ello desvirtúa el hecho de encontrarnos con dos órganos administrativos, con funciones inequívocamente administrativas, ligados y coordinados hasta el punto de corresponder al Alcalde la presidencia del Pleno, así como publicar, ejecutar y hacer cumplir sus acuerdos. No puede hablarse aquí de división de poderes, sino simplemente de la distribución de competencias propia de toda organización administrativa (24).

Naturalmente, la superficial semejanza de las relaciones de los órganos municipales con la existente entre los órganos superiores del Estado, y que parece latir en la base de la recepción de la moción de censura en el ámbito local, no se ha llevado al extremo, que hubiera resultado singularmente absurdo, de admitir la posibilidad

electoral. Así, las elecciones municipales podrían constituir un cauce adecuado para canalizar motivaciones de voto distintas a las prevalentes en elecciones de ámbito superior. La regla en España pierde parcialmente relevancia por la consagración del sistema de listas cerradas y bloqueadas y la elección indirecta del Alcalde. Ahora, la moción de censura, en cuanto puede suponer el acceso a la Alcaldía de quienes ocuparon puestos secundarios en las listas y no protagonizaron la campaña electoral, po. tencia la tendencia al voto en función del partido político y no de las personas.

Es de destacar, además, que en este voto en función del partido no es un factor desdeñable el papel de éste en la política nacional, sino que se superpone al de la actuación local y programa municipal concreto del partido. Sobre este tema, Dilys M. Hill: Teoría democrática y Régimen local. Madrid, 1980, págs. 208 y sigs.

(24) Consecuentemente con ello, hablar de parlamentarismo en el Ayuntamiento es equívoco y sólo admisible en sentido figurado para explicar simplísticamente las relaciones entre el Pleno y el Alcalde. Es de destacar, además, la incongruencia que supone calificar a la organización municipal de "presidencial», pues tal término hace referencia a un régimen de relaciones del Ejecutivo con el Legislativo que se contrapone al régimen parlamentario y que nada tiene que ver con las muchas o pocas competencias o poderes del Presidente. 
de «disolver el Pleno» y convocar nuevas elecciones en manos del Alcalde. Ello, además de poner de manifiesto la imposibilidad de trasladar simplistamente a este campo las técnicas propias de relación de los poderes constitucionales, rompe el posible equilibrio en los órganos representativos municipales. Recordamos anteriormente cómo la inexistencia de derecho de disolución convertía al régimen parlamentario en un régimen de asamblea, dado el predominio de ésta sobre el Gobierno. Ahora hay que sumar a ello un dato esencial para comprender cuál puede acabar siendo la función y dinámica real de esta figura en el ámbito local. El Presidente de un Gobierno parlamentario suele ser, al mismo tiempo, el jefe del partido mayoritario, de forma que la posible moción de censura se dificulta: los Diputados de su partido le están, en cierto sentido, subordinados a través precisamente del partido, que directa o indirectamente controla. No casualmente moción de censura y disciplina de voto van normalmente unidas. Pero nada de ello podrá predicarse de la mayoría de los Alcaldes, que generalmente no detentan puestos relevantes en el aparato de los partidos políticos. Para ellos, lejos de derivar en un reforzamiento de su situación tendente a la disciplina de voto de los Concejales de su partido, la posibilidad de la moción de censura supondrá una sumisión absoluta a las directrices de los partidos, sin la cual la destitución podrá ponerse fácilmente en marcha.

La moción de censura, no parece difícil preverlo, se convertirá en un arma del mismo partido del Alcalde para garantizar la disciplina de éste. Los burócratas o las bases de los partidos políticos se constituyen así en el verdadero control de la actuación del Alcalde. Una gestión municipal incómoda para el partido o los órganos superiores de la Administración del Estado, regional o provincial, detentados por miembros del mismo partido político, pero generalmente con más poder en su organización interna, será más fácilmente causa de mociones de censura que una efectiva pérdida de confianza de los Concejales. La exigencia de la mayoría absoluta del número legal de Concejales —que prácticamente imposibilita la censura sin el concurso del partido mayoritario, que normalmente será el del Alcalde censurado- y la ampliación de los candidatos a todos los Concejales - lo que aumenta la maniobrabilidad del partido- parecen confirmar esta previsión sobre el resultado final de la moción de censura en nuestra Vida local.

En suma, pues, la posibilidad de destitución del Alcalde por los 
Concejales podrá considerarse una medida necesaria ante su configuración como órgano prepotente del Municipio en la Ley Reguladora de las Bases del Régimen local; podrá considerarse, y lo es efectivamente, una solución a las crisis municipales, a las situaciones de Alcaldes que pierden la confianza de los Concejales o que incurran en una gestión gravemente dañosa para la Entidad local, y que, además, se trata de una solución formalmente respetuosa con la autonomía municipal. Pero debe tenerse en cuenta también en qué medida puede ser su misma admisión provocadora de inestabilidad y de crisis artificiales, tanto por su inadecuación al sistema de relación entre Pleno y Alcalde, como por su no armonización con la forma de elección de éste. Especialmente debe ponerse de manifiesto que la admisión de la moción de censura en el ámbito local aleja al electorado del nombramiento del titular del órgano municipal de mayor relevancia, aumentando correlativamente el protagonismo de los partidos políticos, que por esta vía podrán colocar al frente de los Ayuntamientos a hombres sin relieve o, en general, más adecuados a los intereses de su política extralocal. En esta línea, quizá no sea aventurado conectar la moción de censura con el "vacío» producido por la inconstitucionalidad (25) y final derogación del artículo 11, 7, de la Ley de Elecciones locales de 1978, que permitía, mediante la expulsión del partido político, la destitución como Concejal y Alcalde. En cualquier caso, lo cierto es que el "Alcalde fuerte» de la nueva Ley lo es con este límite de la moción de censura, que no muy remotamente le conecta con su propio partido político (26).

(25) Sentencias del Tribunal Constitucional de 4 de febrero de 1983 (Boletín Oficial del Estado de 9 de marzo) y de 21 de febrero de 1983 (Boletin Oficial del Estado de 23 de marzo).

(26) Son reveladoras las palabras del Senador Izouierdo Collado, con las que terminó el debate sobre el artículo 197 de la LOREG: «... los partidos políticos van a tener que hacer un esfuerzo grande a la hora de componer sus listas electorales, con el fin de que aquellas personas que ellos presentan sean personas que tienen muy claro el programa de ese partido, que tienen muy clara la relación y la vinculación con el partido...» (Sesión Plenaria núm. 124, de 28 de mayo de 1985; Diario de Sesiones del Senado, año 1985, núm. 124, pág. 5836). Es precisamente con la finalidad de destituir de la presidencia de la Corporación a quienes no tengan «clara» su vinculación con el partido - y su subordinación con las jerarquías de éste- para la que se instituye la censura.

Sería ingenuo considerar que el depositar en manos de los Concejales la destitución del Alcalde nada tiene que ver con un control del partido respectivo, pues, como señala HILL, op. cit., pág. 215, «los Consejeros se consideran a sí mismos como representantes de un partido y de su doctrina, tanto como de sus electores concretos...». 
4. LA MOCIÓN DE CENSURA COMO MATERIA RESERVADA

\section{A LA LEY ORGáNICA}

Especial atención merece la inclusión o no en las materias enumeradas en el artículo 81 de la Constitución como reservadas a la Ley Orgánica, y concretamente en el «régimen electoral general», de la moción de censura.

La cuestión, como se indicó al principio de este trabajo, ha provocado, en el debate parlamentario, el cambio de ubicación de la figura, que ha pasado de una Ley ordinaria a una Ley Orgánica aprovechando la coincidencia de la simultánea tramitación de la Ley Electoral (27).

Esta inclusión en una Ley Orgánica no exime de ciertas justificaciones y explicaciones, toda vez que, en principio, no prejuzga absolutamente la solución. Tanto la reserva de la Ley Orgánica a las materias enumeradas en el artículo 81 de la Constitución (28), como la posible consideración de la moción de censura como materia conexa al «régimen electoral general» y no propiamente incluida en él (29), exigen plantearse el tema con independencia de la solución dada por el legislador.

El problema ha de solventarse desde la perspectiva del contenido, significado y efectos de la moción de censura, para, conforme a ello, determinar si forma parte del régimen electoral general $\mathbf{y}$, consecuentemente, de las materias reservadas a la Ley Orgánica por el artículo 81 de la Constitución.

Rechazamos así el enfoque de la cuestión desde el punto de vista de la modificación o no de la legislación electoral anteriormente vi-

(27) La cuestión fue planteada en el debate de la Ley Reguladora de las Bases del Régimen local en la Comisión del Congreso de Régimen de las Administraciones Públicas, sesión de 19 de octubre de 1984, acordándose elevar a la Mesa de la Cámara la consulta (Diario de Sesiones del Congreso de los Diputados, año 1984, núm. 223, páginas 6934 y sigs.). Fue, finalmente, en el trámite de Ponencia del Senado donde se convirtio el artículo 22, 3 , en una remisión a la legislación electoral (Boletín Oficial de las Cortes Generales, Senado, serie II, núm. 215, d), de 12 de febrero de 1985, página 287).

(28) Es conocida la jurisprudencia constitucional según la cual «si es cierto que existen materias reservadas a las Leyes Orgánicas..., también lo es que las Leyes Orgánicas están reservadas a estas materias y que, por tanto, sería disconforme con la Constitución la Ley Orgánica que invadiera materias reservadas a la Ley ordinaria» (sentencia del Tribunal Constitucional de 13 de febrero de 1981, fundamento jurídico 21, A, Boletín Oficial del Estado de 24 de febrero).

(29) «La posibilidad de inclusión en una Ley Orgánica de materias no reservadas a ésta por razones de conexión temática o de sistematicidad o de buena política legislativa», la admitió ya el Tribunal Constitucional en su sentencia de 13 de febrero de 1981, fundamento jurídico $21, \mathrm{~B}$. 
gente. Quiere señalarse con ello que la llamada invulnerabilidad de las Leyes Orgánicas - «efecto de congelación de rango», en equívoca expresión del Tribunal Constitucional (30) - es, en principio, un efecto accesorio y derivado de la reserva constitucional de Ley Orgánica, que sólo alcanza efectos propios en los casos de materias conexas, y aun así, muy reducidos, ya que pueden ser excluidos por la propia Ley Orgánica o por sentencia del Tribunal Constitucional (31).

Con ocasión del recurso previo de inconstitucionalidad contra la Ley Orgánica número 6/1983, de 2 de marzo, de Reforma de las Elecciones locales, el Tribunal Constitucional, en su sentencia número 38/1983, de 16 de mayo, afirmó el carácter orgánico de la materia en aquella regulada considerándola incluida en la expresión "régimen electoral general» utilizada por el artículo 81 de la Constitución. Su doctrina constituye un necesario punto de partida en tanto que afirma que «el régimen electoral general está compuesto por las normas electorales válidas para la generalidad de las instituciones representativas del Estado en su conjunto, y en el de las Entidades territoriales en que se organiza, a tenor del artículo 137 de la Constitución española...», y entre ellas se encuentra inequívocamente el Alcalde. Igualmente se señala que «el artículo 140 (al igual que el art. 68,1) reserva a la Ley el régimen de las elecciones locales en los aspectos que dice (entre ellos, la elección de Alcalde), Ley que por la misma exigencia del artículo 23,1 , y la precisión que hace el artículo 81, 1, entendido en relación con los artículos 68,1 , y 140, ha de ser una Ley Orgánica. Se reserva así a la Ley —a la Ley Orgánica- el régimen electoral general, tanto de las elecciones que tienen en los artículos 67 al 70 sus líneas constitucionales, como de las elecciones que las tienen en el artículo 140" (entre ellas, las del Alcalde). Revelador es, igualmente, el que esta sentencia no contenga exclusión de ninguno de los preceptos de la Ley de Reforma del carácter orgánico. Es más, pese al heterogéneo contenido de su articulado, que en algunos puntos está relativamente alejado del tema electoral, no se plantea siquiera la posibilidad de indicar si algunos preceptos de los contenidos en la Ley Orgánica podrían ser modificados por Leyes ordinarias, posibilidad ésta expresamente reconocida en la sentencia del mismo Tribunal de 13 de febrero de 1981 (fundamento jurídico 21 , a) y c) ).

(30) Sentencia de 13 de febrero de 1981, fundamento jurídico 21.

(31) Sentencia de 13 de febrero de 1981, fundamento jurf́dico 21. 
A la vista, pues, de esta sentencia de 20 de mayo de 1983, la regulación de las elecciones locales es materia reservada a la Ley Orgánica, y todo el contenido de la Ley de Reforma de 2 de marzo de 1983 tenía aquel carácter electoral y naturaleza orgánica. Pese a todo, no parece que pueda deducirse que a cualquier contenido de una Ley de Elecciones haya de dársele el mismo carácter. Concretamente, la Ley número 39/1978, de 17 de julio, aprobada con anterioridad a la Constitución y sin el carácter de orgánica, regulaba algunos aspectos que, más que electorales, pudieran considerarse de organización municipal y provincial. Si el Tribunal Constitucional ha desechado la «concepción formal de la Ley Orgánica» atendiendo al real contenido de la Ley con independencia de su etiquetación y procedimiento de aprobación parlamentaria, resultaría absurdo que su simple denominación como «Ley de Elecciones locales» bastase para caracterizar todo su contenido y hacer a éste inalterable por Ley ordinaria, eximiendo de otros análisis. Por el contrario, es necesario precisar, en concreto, si la designación del Alcalde forma parte del «régimen electoral general»; posteriormente, si la moción de censura es asimilable a aquella materia.

Con respecto a lo primero, podría justificarse la exclusión de la reserva de Ley Orgánica en la medida en que se considere que no puede verdaderamente hablarse de elecciones en cuanto al Alcalde, siendo su designación resultado de un acuerdo del Pleno; no habría una elección de representantes, sino un acto de éstos en calidad de tales; no habría ejercicio del derecho reconocido en el artículo 23, 1 , de la Constitución, como no lo hay en los restantes acuerdos de los Concejales; no podría hablarse propiamente, en este caso, ni siquiera de elección de segundo grado. Pese a ello, parece forzado recoger la solución contraria por las siguientes razones:

A) Cuando no se da la mayoría absoluta, la designación de Alcalde deriva directamente del resultado electoral (arts. 28, 3, c), de la LEL de 1978, y 196, c), de la LOREG).

B) Aunque así no fuera, la opción establecida en el artículo 140 de la Constitución («los Alcaldes serán elegidos por los Concejales o por los vecinos») requiere un mismo instrumento normativo sea cual fuere el sistema a seguir: sería absurdo que para atribuir a los Concejales la elección de Alcalde bastase la Ley ordinaria, pero para establecer un sistema de elección directa por los vecinos resultase 
necesaria una Ley Orgánica por entrar indudablemente en el «régimen electoral general».

C) La doctrina del Tribunal Constitucional contenida en la citada sentencia de 16 de mayo de 1983, en tanto que, aunque se optase por un sistema puro de elección indirecta, estaríamos ante normas que tienen sus «líneas constitucionales» en el artículo 140 y que se refieren a la elección de instituciones representativas de las Entidades territoriales.

Mayores dudas suscita el tema que nos ocupa, esto es, si la moción de censura, en tanto que íntimamente ligada con la anterior cuestión de elección de Alcalde - que por ello ha sido analizada-, es también materia reservada a la Ley Orgánica. En principio, parece difícil su inclusión en el régimen electoral general, pues verdaderamente el proceso electoral queda aquí al margen. Parece, y así la presenta la Ley Reguladora de las Bases de Régimen local, que nos encontramos simplemente ante una competencia del Pleno, ante un aspecto estrictamente organizativo que hace referencia a las relaciones entre los órganos municipales. Junto a estos dos argumentos ha de ser recordado el criterio restrictivo mantenido en la sentencia del Tribunal Constitucional de 5 de agosto de 1983: «El hecho de que el legislador constituyente haya optado por determinaciones específicas de reserva de Ley Orgánica, y no por una previsión generalizada, hace imposible la extensión de esas reservas a otras materias por considerarlas de análoga importancia... La exigencia de (mayorías) cualificadas... sólo puede tener carácter excepcional y ha de ser explícitamente prevista en la Constitución...».

Sin embargo, parece haber motivos suficientes para considerar que la recepción y regulación de la moción de censura exige Ley Orgánica. Lo contrario desvirtuaría, hasta hacerla inoperante, la exigencia de mayoría absoluta para determinar el sistema de elección de Alcalde. Dicho más simplemente, sería absurdo que el legislador con una simple mayoría pudiera establecer un procedimiento de destitución del Alcalde elegido en virtud de un sistema determinado por Ley Orgánica. Piénsese, por ejemplo, que si una Ley Orgánica de elecciones estableciese la elección directa del Alcalde por los vecinos, no tendría sentido imposibilitar a una Ley ordinaria modificar tal sistema y permitirle, al mismo tiempo, introducir un sistema de destitución por decisión de los Concejales, que haría virtualmente ineficaz el resultado de las elecciones de Alcalde. $\mathrm{Pa}$ - 
rece, pues, que un mínimo de congruencia exige extender la reserva del «régimen electoral general» en favor de la Ley Orgánica a la regulación inmediatamente relacionada con la efectividad del resultado electoral.

Los anteriores argumentos se refuerzan cuando lo que se trata de introducir es la moción constructiva que establece un nuevo procedimiento de elección de Alcalde. Desde este punto de vista, no parece siquiera forzar la expresión «régimen electoral general» la inclusión de la moción de censura. Esta, no cabe duda, habría de encontrar sus "líneas constitucionales» en el artículo 140 y afectaría a la elección, no sólo destitución, de «instituciones representativas» de las Entidades territoriales, por lo que, de acuerdo a la doctrina de la reiterada sentencia del Tribunal Constitucional de 16 de mayo de 1983, habría que concluir en su carácter orgánico.

Por otra parte, el argumento de que se trata de un simple aspecto organizativo es, cuando menos, equívoco. Los temas electorales son, en gran medida, de organización, de tal forma que resultan difícilmente separables. También podría plantearse como una simple competencia del Pleno el nombramiento de Alcalde y ello no podría desvirtuar su carácter electoral $\mathrm{y}$, consecuentemente, reserva de Ley Orgánica. De hecho, en la Ley Orgánica 6/1983, de Reforma de las Elecciones locales, se recogía la elección del Presidente de la Diputación y el Tribunal Constitucional no realizó pronunciamiento alguno contra su carácter orgánico.

No hay tampoco, en realidad, en esta inclusión de la moción de censura constructiva en la reserva de Ley Orgánica, nada que se oponga al criterio restrictivo acogido por el Tribunal Constitucional, pues no se trata de incluir otra materia por considerarla de análoga importancia, sino de una interpretación extensiva, lógica y sistemática de la expresión «régimen electoral general». Lejos de incurrir en la analogía rechazada en este tema por la sentencia del Tribunal Constitucional de 5 de agosto de 1983, la interpretación extensiva que se propone encuentra su apoyo en la misma razón de la doctrina constitucional: Si «la rigidez del ordenamiento jurídico no puede llevarse más allá de los supuestos específicamente tasados», y ello veda la ampliación por analogía de la reserva de Ley Orgánica, ningún inconveniente puede verse a una interpretación de las materias enumeradas en el artículo 81 de la Constitución que conduzca a hacer real y efectiva la rigidez expresamente prevista por la misma Constitución, como ocurre en el caso de la elección 
de Alcalde y su moción de censura. En realidad, el mismo Tribunal Constitucional, pese al expuesto criterio contrario a la analogía, no ha tenido inconveniente, en su sentencia de 20 de mayo de 1983, en interpretar ampliamente, quizá excesivamente, la expresión "régimen electoral general» incluyendo toda la legislación de elecciones locales, frente a lo sostenido por un amplio sector doctrinal que refería la expresión a las elecciones generales o legislativas (32).

\section{LA MOCION DE CENSURA AL PRESIDENTE DE LA DIPUTACION. REFERENCIA A LAS MANCOMUNIDADES INTERINSULARES, CABILDOS Y CONSEJOS INSULARES}

En todo momento, la regulación de la moción de censura al Presidente de la Diputación ha corrido idéntica suerte en el debate parlamentario - hasta consagrarse en los artículos 207, 3, de la Ley Orgánica de Régimen Electoral General, y 33, 3, de la Ley Reguladora de las Bases del Régimen local- que la referente al Alcalde. La remisión en su contenido al correspondiente artículo en el ámbito municipal así lo exigía.

Así, puede igualmente trasladarse aquí cuanto antes se señaló sobre la reserva de la materia a la Ley Orgánica.

No parece, por el contrario, que las críticas antes realizadas con respecto a la moción de censura al Alcalde puedan extenderse a su recepción en la Diputación. El distinto carácter de las elecciones provinciales, y especialmente de su Presidente, hacen posible y útil su consagración. Hubiera sido, sin embargo, preferible hablar simplemente de destitución, como hacía el artículo 34,3 , de la Ley de Elecciones locales de 1978, y no de moción de censura, expresión ineludiblemente unida al régimen parlamentario y fuera de lugar en la Administración local.

Interesa, no obstante, hacer algunas precisiones específicas respecto de la moción de censura del Presidente de la Diputación; particularmente, en lo que se refiere a las Entidades en que su regulación resulta aplicable y al período transitorio hasta su efectiva entrada en vigor.

En cuanto a lo primero, hay que empezar por recordar, conforme

(32) Puede verse una completa síntesis de las distintas interpretaciones doctrinales de la expresión «régimen electoral general», anteriores a la comentada sentencia del Tribunal Constitucional, en Cosculluela MonTANer, L. M.: La Ley de Reforma de las Elecciones locales (Comentarios a la Ley de 2 de marzo de 1983). Madrid, 1983, páginas 9 y sigs. 
se indicó ya anteriormente, la existencia de normas específicas para las Provincias vascas sobre moción de censura de su Diputado general (33), normas que establecen una regulación más completa y no enteramente coincidente con la de la Ley Orgánica de Régimen Electoral General. Tal regulación prevalece de acuerdo con el artículo 39 de la Ley Reguladora de las Bases del Régimen local, según el cual: «Los órganos forales de Alava, Guipúzcoa y Vizcaya conservan su régimen peculiar en el marco del Estatuto de Autonomía de la Comunidad Autónoma del País Vasco». A la misma conclusión conduce la Disposición Adicional segunda, 1, de la citada Ley, que establece que «... los Territorios Históricos de Alava, Guipúzcoa y Vizcaya organizarán libremente sus propias instituciones y dictarán las normas necesarias para su funcionamiento...», y más claramente, por su inclusión en Ley Orgánica, el artículo 209 de la de Régimen Electoral General, que deja expresamente a salvo los «regímenes especiales autonómicos y forales». Frente a ello no puede prevalecer la genérica declaración de la Disposición Adicional primera, 4, que, naturalmente, ha de entenderse con la salvedad expresada.

Dejando al margen el tema de la moción de censura en las Comunidades Autónomas uniprovinciales, que, evidentemente, responde a otra lógica y regulación y que queda fuera del objeto de este trabajo, reducido a su operatividad en la Administración local, sí es necesario aludir a esta técnica de destitución en las Mancomunidades provinciales interinsulares, Cabildos insulares de Canarias y Consejos insulares de Baleares.

Las Mancomunidades interinsulares de Canarias, pese a ser consideradas "como órganos de representación y expresión de los intereses provinciales" (art. 41, 2, de la Ley Reguladora de las Bases del Régimen local), no son asimilables de ninguna forma a las Diputaciones, ni puede afirmarse les corresponda «el gobierno y administración autónoma de la Provincia» (art. 31, 3, LRBRL), por lo que carece de sentido aplicarles las normas previstas para aquéllas. Lo anterior se hace especialmente claro en lo que se refiere a la moción de censura de su Presidente, dada la forma de su designación y la composición de la Mancomunidad, prevista en el artículo 41, 2, de la repetida Ley Reguladora de las Bases del Régimen local: «Integran dichos órganos los Presidentes de los Cabildos insulares de las Provincias correspondientes, presidiéndolos el del

(33) Véase la anterior nota 10. 
Cabildo de la Isla en la que se halle la capital de la Provincian. Ni la reducida significación de esta presidencia ni su atribución automática por criterios no electorales permiten siquiera sostener la duda, y consecuentemente con ello, no hay aquí alusión legal alguna a la moción de censura.

Respecto a los Cabildos y Consejos insulares, el problema se plantea desde el momento en que el artículo 41 de la Ley Reguladora de las Bases del Régimen local establece para ambos que se rigen por las normas que regulan la organización y funcionamiento de las Diputaciones provinciales (párrafos 1 y 3). Es esta remisión la que justifica aquí su tratamiento conjunto con la censura en la Diputación, pese a tratarse de Entes de naturaleza diferente. ¿Puede llevar el referido artículo 41 a entender que es posible la moción de censura a los Presidentes de los Cabildos y Consejos insulares? Entendemos que la respuesta debe ser negativa, pues aunque la expresión «organización y funcionamiento» pudiera incluir a la moción de censura, el carácter electoral dado a la materia y la consiguiente reserva de Ley Orgánica inclinan a optar por su exclusión. Dicho de otra forma, si la moción de censura se ha considerado acertadamente, por su naturaleza electoral, materia regulable únicamente por Ley Orgánica, no puede interpretarse al mismo tiempo que el contenido de una Ley ordinaria esté haciendo pronunciamientos sobre esta fórmula de destitución. Así, el silencio a este respecto de la Ley Orgánica 5/1985, de 19 de junio, debe equipararse a negación de la moción de censura en este ámbito.

Por otra parte, la atribución de la presidencia de los Cabildos insulares canarios al «candidato primero de la lista más votada en la circunscripción insular» (art. 201, 5, de la Ley Orgánica de Régimen Electoral General) refuerza la conclusión anterior, pues resulta incongruente atribuir poder de destitución a quien no eligió al Presidente, máxime si éste deriva su condición directamente de los votos populares. Lo contrario, a mayor abundamiento, haría virtualmente inoperante el sistema de elección previsto en el citado párrafo 5 del artículo 201, o peor aún, lo convertiria en un mero trámite para elegir, finalmente, a quienes los Consejeros considerasen oportuno (34).

(34) Difícil resulta, sin embargo, trasladar este argumento a los Consejos insulares de Baleares. La regulación de la elección de los miembros de éstos se contiene en el artículo 37 del Estatuto de Autonomía, aprobado por Ley Orgánica 2/1983, de 
La Disposición Transitoria tercera de la Ley Orgánica de Régimen Electoral General, que, como se indicó antes para el Alcalde, pospone la aplicabilidad de su regulación de la moción de censura a la celebración de elecciones locales tras su entrada en vigor, abre la interrogante de si hasta ese momento no es admisible plantear la moción de censura o si, por el contrario, puede hacerse de acuerdo a lo establecido en el artículo 34, 3, de la Ley de Elecciones locales de 1978.

No parece que la intención del legislador -claramente favorable a la moción de censura, como demuestra la disminución de los requisitos necesarios para que prospere- fuese suprimir durante dos años lo que ya permitía la legislación anterior. Sin embargo, la derogación expresa y total de la Ley de Elecciones locales (Disposición Derogatoria de la LOREG) impide aplicar su artículo 34, 3, durante este período. Por tanto, se produce la paradójica consecuencia de que para pasar de una posibilidad restringida de destitución a otra de mayor amplitud, se establece un período intermedio de negación pura y simple de la competencia del Pleno para destituir al Presidente. Ello, claro está, sin perjuicio de que se admita por vía jurisprudencial, de forma similar a como se hizo con el Alcalde.

25 de febrero, artículo que sustituía, antes de nacer, al 39 de la Ley de Elecciones locales, en la redacción dada por Ley Orgánica 6/1983, de 2 de marzo, conforme se explicitaba en la transición séptima de la citada Ley de Elecciones. Pero nada se dice en el artículo 37 del Estatuto Balear de la forma de elección del Presidente de los Consejos, por lo que, en este punto, podía entenderse aplicable todavía el 39 de la Ley de Elecciones locales, que, a su vez, remitía al 34, 2, sobre elección del Presidente de la Diputación. Ahora, tras la derogación de la Ley de Elecciones locales, y con el silencio de la Ley de Régimen Electoral General, la cuestión de la moción de censura resulta problemática. 